\title{
The Human Nephron Filter: Toward a Continuously Functioning, Implantable Artificial Nephron System
}

\author{
Allen R. Nissenson ${ }^{a}$ Claudio Ronco ${ }^{b}$ Gayle Pergamit ${ }^{c}$ Martin Edelstein $^{c}$ \\ Richard Watts ${ }^{\mathrm{C}}$ \\ a Department of Medicine, Division of Nephrology, David Geffen School of Medicine, Los Angeles, Calif., USA; \\ ${ }^{b}$ Department of Nephrology, St. Bortolo Hospital, Vicenza, Italy, and ${ }^{\mathrm{c} B i o p h i l t r e, ~ I n c ., ~ B u r l i n g a m e, ~ C a l i f ., ~ U S A ~}$
}

\section{Key Words}

Dialysis · Nanotechnology $\cdot$ Membranes .

Hemodialysis $\cdot$ Renal replacement therapy

\begin{abstract}
Background: Nearly 900,000 patients worldwide have end-stage renal disease and require dialysis or kidney transplantation, and this number is expected to more than double by 2010, placing considerable stress on healthcare systems throughout the world. Despite the availability of these forms of renal replacement therapy for nearly four decades, mortality and morbidity is high and patients often have a poor quality of life. Methods: We have developed a human nephron filter (HNF) utilizing nanotechnology that would eventually make feasible a continuously functioning, implantable artificial kidney. The device consists of two membranes operating in series within one device cartridge. The first membrane mimics the function of the glomerulus, while the second membrane mimics the function of the renal tubules. Findings: The device has been computer-modeled and operating $12 \mathrm{~h} /$ day, 7 days/week, the HNF provides the equivalent of $30 \mathrm{ml} / \mathrm{min}$ glomerular filtration rate (compared to half that amount for conventional thrice weekly
\end{abstract}

hemodialysis). Conclusions: The HNF system, by eliminating dialysate and utilizing a novel membrane system created through applied nanotechnology may represent a breakthrough in renal replacement therapy based on the functioning of native kidneys. The enhanced solute removal and wearable design should substantially improve patient outcomes and quality of life.

Copyright (C) 2005 S. Karger AG, Basel

\begin{abstract}
'You see things; and you say "Why?" But I dream things that never were; and I say, "Why not?".'
\end{abstract}

George Bernard Shaw

The epidemic of end-stage renal disease (ESRD) continues worldwide, with the most recent data from the United States Renal Data System showing that nearly 900,000 patients are currently on dialysis or surviving with a functioning kidney transplant [1]. The vast majority of patients are treated with intermittent hemodialysis. However, intermittent, diffusion-based renal replacement therapy (RRT) is widely acknowledged to be unphysiological and associated with high mortality and morbidity $[1,2]$. Recent attempts to improve these out-

\section{KARGER \\ Fax +4161306 1234 E-Mail karger@karger.ch} www.karger.com
C 2005 S. Karger AG, Basel 0253-5068/05/0234-0269\$22.00/0

Accessible online at:

www.karger.com/bpu
Allen R. Nissenson

UCLA Medical Center

200 Medical Plaza, Suite 565

Los Angeles, CA 90095 (USA)

Tel. +1 310825 9464, Fax +1 310206 2985, E-Mail anissenson@mednet.ucla.edu 
comes have focused on incremental changes in the current dialysis technologies. Increasing the frequency and/ or duration of dialysis utilizing diffusive dialytic techniques and user-friendly delivery machines have been advocated by some [3-9]. Others have developed convective forms of therapy utilizing high-efficiency and highflux dialyzers in a variety of configurations, some combined with diffusive solute removal as well $[10,11]$.

Modality selection remains primarily driven by reimbursement throughout the world [12,13], in part because a compelling clinical case for one modality over another has not been made. The advances in technical delivery of dialysis that have been seen in the past decade have resulted in better patient tolerance to therapy, but have had little impact on primary outcomes such as mortality.

Over the past 30 years developments in hemodialysis have been focused on improved biomaterials, primarily for the disposable components such as dialyzers, and enhancement of the design of dialysis delivery machines, the latter leading to safer, better tolerated treatments [8, $9,14]$. The introduction of increasingly sophisticated machines and manufacturing procedures $[15,16]$ has taken place in parallel with a significant reduction in the size of clinical dialyzers. Much of this progress has been driven by improved understanding of the physiological effects and consequences of dialysis at a micro-scale level, leading to superior blood circuit design, smooth and biocompatible blood pathways, standardized thickness and porosity of membranes, and more accurate alarms and safety controls.

Modern dialysis, as a result of the developments described, is carried out with dialyzers with minimal blood priming required, constant and reproducible performance and minimal dialytic loss of essential constituents such as albumin, despite significantly greater clearance characteristics for small- and medium-sized solutes compared to previously available dialyzers. Further increases in dialyzer efficiency, however, are increasingly difficult, in large part because of the nonselective nature of current conventional membranes, except on the basis of solute molecular size. Research in this area is now focused on the development of a new type of membrane, the pores of which selectively transport solutes, independent of molecular weight.

In an attempt to significantly improve on current outcomes of ESRD patients, we developed a series of specifications for an ideal RRT device. Such a device would mimic the function of natural kidneys - it would be continuously operating; remove solute with a molecular weight spectrum like natural kidneys; it would be flexible and remove water and solute based on individual patient needs; it would be wearable or implantable and therefore transparent to the patient; and it would be biocompatible. In addition, it would be lightweight, low cost, safe and reliable. In order to achieve these ambitious specifications we applied nanotechnology to the development of a renal replacement device, the human nephron filter or HNF, which begins to meet these specifications [17].

Nanotechnology, as defined by Drexler [18], refers to atomically precise functional machine systems developed on the scale of the nanometer (one billionth of a meter: $1 \mathrm{~nm}=1 / 1,000,000,000 \mathrm{~m}$ ). Research in this field is exploding, with a recent national commitment in the United States to focus government funding in this area. Using nanotechnology it should be possible to design tiny tools to safely and effectively repair tissues or biomaterials [19]. The application of this science to biomedicine is known as nanomedicine, defined as the monitoring, repair, construction and control of human biological systems at the molecular level using engineered nano-devices and nano-structures. The number of such applications is endless [20].

Most current work is beginning to capture benefits by focusing on the nanoscale: moving materials down into the nanoscale size range, although lacking the atomic precision of true nanotechnology. Some examples of this nanoscale application to RRT are already appearing, the first the recent introduction by Fresenius Medical Care of the Helixone ${ }^{\circledR}$ membrane [21]. This is a polysulfonebased, high-flux membrane in which the porosity of the inner layer is finely controlled at the level of nanoscale. This membrane is produced using a nanocontrol spinning procedure which produces a significant effect on the structure of the skin layer of the membrane at the nanoscale level. The result is an increased number of pores, while the spectrum of pore diameters is narrowed and concentrated around the desired values. This enables increased removal of medium-sized molecules such a $\beta_{2^{-}}$ microglobulin, while the sieving for albumin has been reduced with virtually no leak of albumin at all. The nanocontrol spinning procedure has made possible the refined control of the number, diameter, and anatomical characteristics of the pores. This is the first device working in the nanoscale for RRT, and highlights the enormous potential of this approach.

The HNF, however, is the initial application of atomically precise nanotechnology to RRT. The HNF consists of two membranes operating in series within one device cartridge. The first membrane, the $\mathrm{G}$ membrane, mimics the function of the glomerulus, using convective transport 


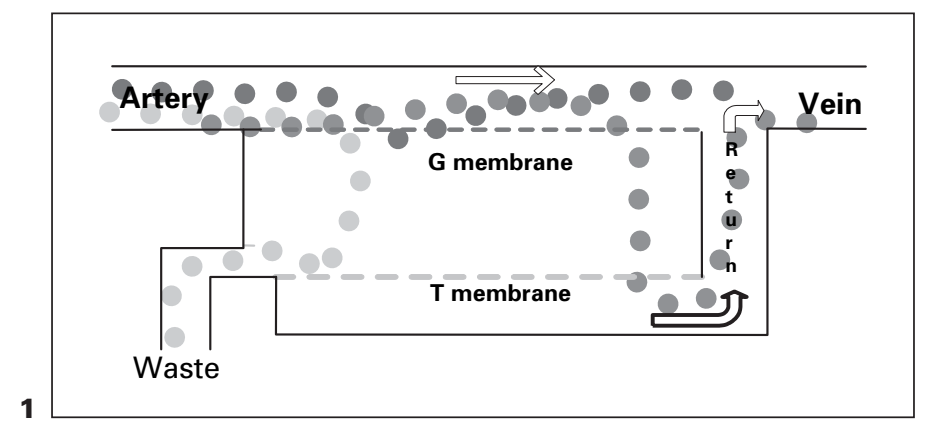

Fig. 1. The human nephron filter.

Fig. 2. The human nephron filter wearable system.

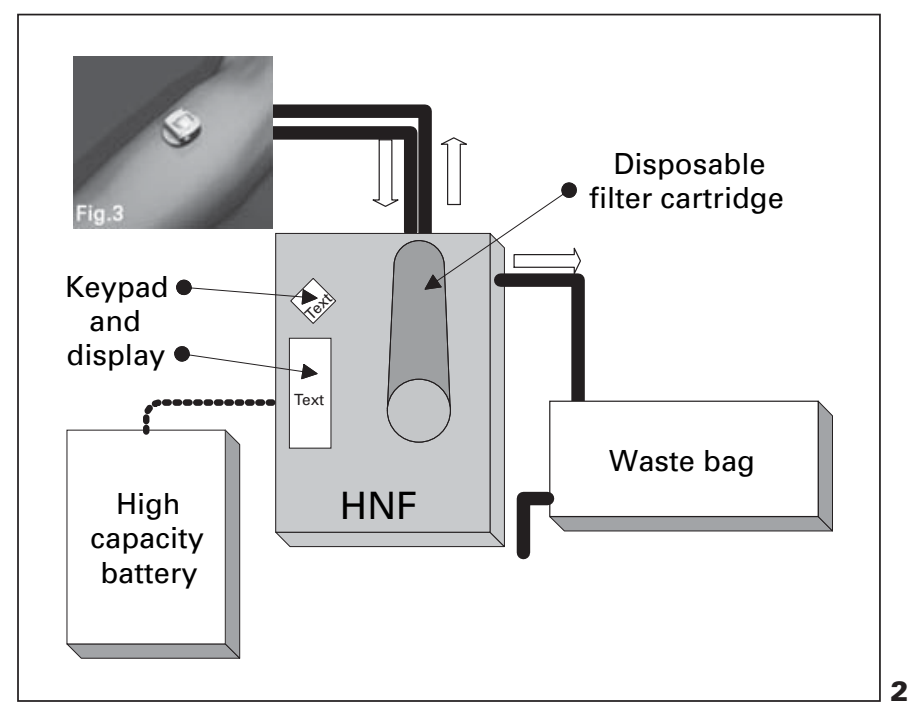

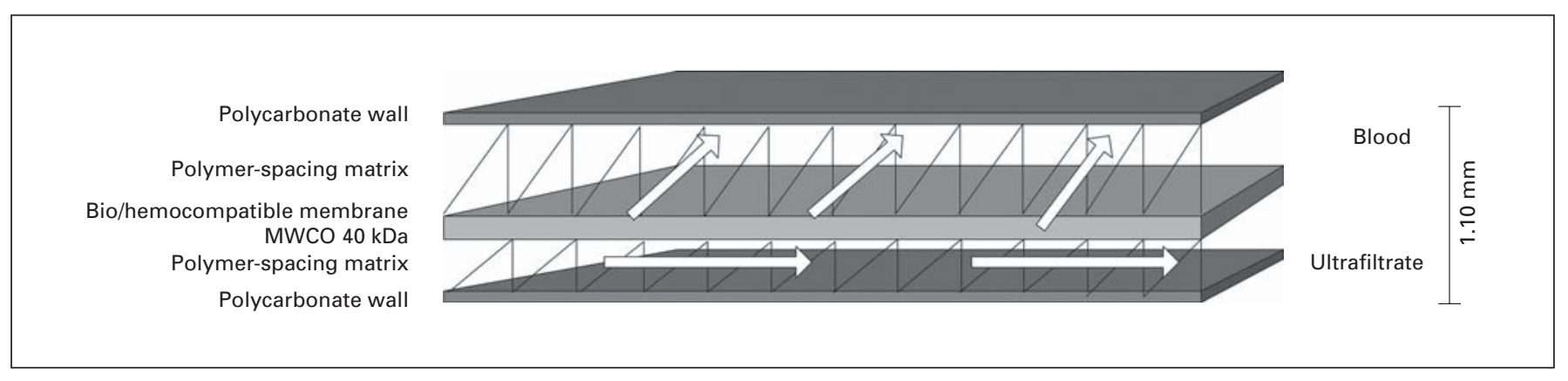

Fig. 3. The G membrane.

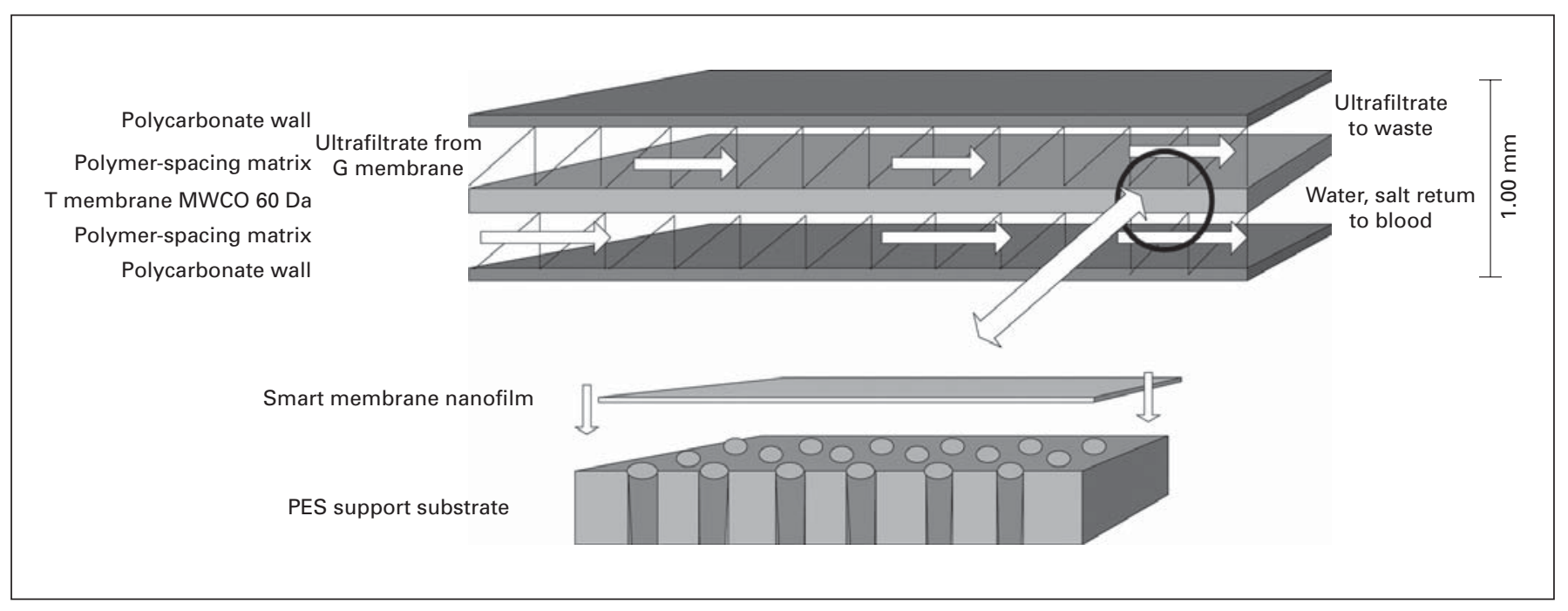

Fig. 4. The $T$ membrane. 


\section{SMART MEMBRANES}

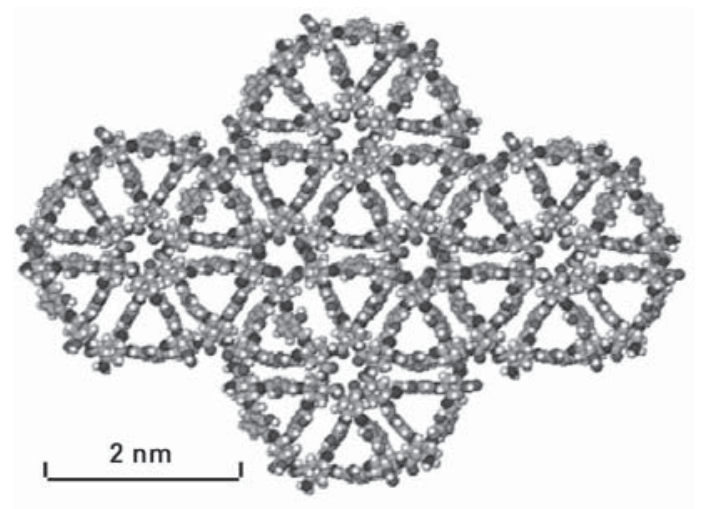

- Selective transport

- Predetermined/controlled pore size

- Atomically engineered pore size/functionality

- Ultra-thin active filtration layer

\section{POLYMER MEMBRANES}

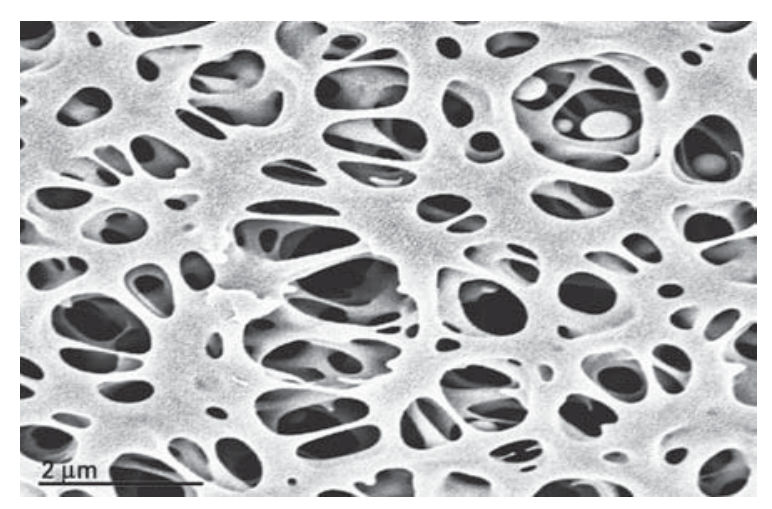

- Unselective transport

- Wide distribution of pore sizes

- No opportunity for precise atomic placement

- Relatively thick, often low flux

Fig. 5. Membrane technology.

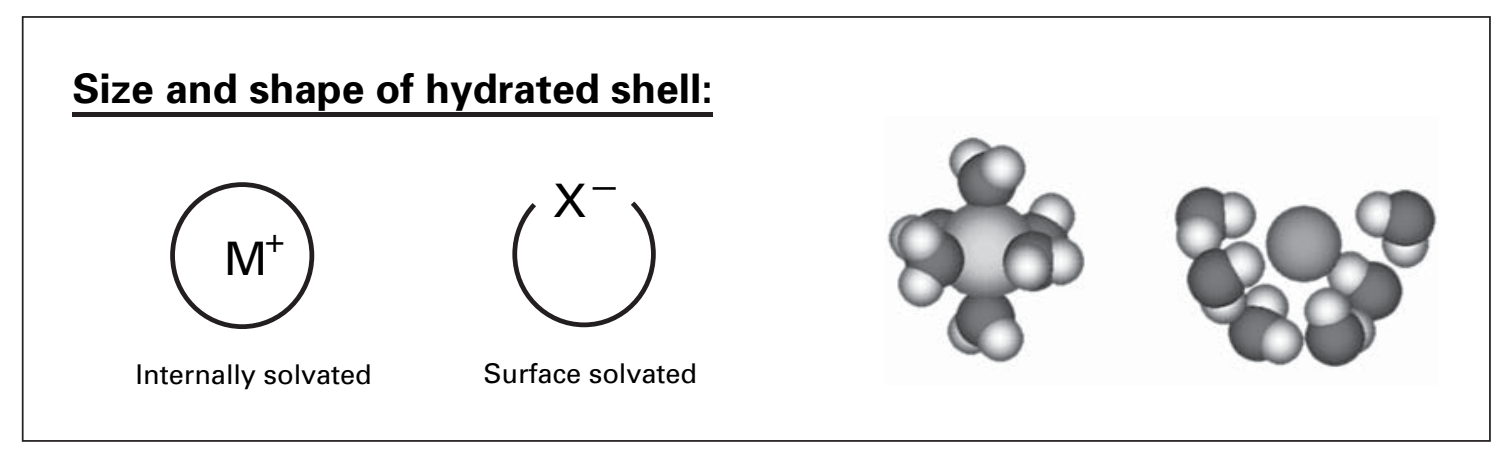

Fig. 6. Ion hydration and pore interaction.

to generate a plasma ultrafiltrate containing all solutes approaching the molecular weight of albumin (fig. 1). The second membrane is the $\mathrm{T}$ membrane, the smart membrane, which mimics the function of the renal tubules, selectively reclaiming designated solutes to maintain body homeostasis, again by convection. No dialysate is used in this system. The cartridge with the membranes is part of a wearable system that includes a keypad and dis- play, a high-capacity battery, and a waste bag (fig. 2). The entire device is wearable, slightly larger than a natural human kidney, and weighs about $3.2 \mathrm{~kg}$ in its initial version.

Once blood access is obtained, blood is pumped at $100 \mathrm{ml} / \mathrm{min}$ across the $\mathrm{G}$ membrane. A deconstructed mock-up of this membrane is shown in figure 3 , with the polycarbonate wall and polymer-spacing matrix shown 
for purposes of illustration only. Note that the entire thickness of the membrane and support materials is approximately $1 \mathrm{~mm}$. The total surface area needed is just over one tenth of a square meter.

The $\mathrm{T}$ membrane is depicted in figure 4. At the top, note the sandwich approach similar to that used for the $\mathrm{G}$ membrane. The T membrane itself, as shown in the middle section of figure 4 is supported on a substrate and contains the smart pores that make this technology unique. The total surface area need is just over one hundredth of a square meter. The membrane consists of approximately $1.6 \times 10^{16}$ pores, $1-5 \mathrm{~nm}$ apart. Pores can be constructed in various sizes and shapes. Although the initial $\mathrm{T}$ membranes will be developed with only one type of pore, we are in the process of developing a pore library that will permit custom membranes to be produced, depending on patient needs.

Figure 5 illustrates a few of the key differences between the smart membranes, shown on the left, and conventional polymer membranes, shown on the right. Smart membranes have selective transport characteristics, contain a predetermined number and size of pores that are atomically engineered and are not passive, but have specific interaction with solutes (functionality). In addition, the active filtration layer is ultra-thin, the size of a single molecule (about $2.5 \mathrm{~nm}$ ). In contrast, polymer membranes have unselective transport of solutes, a wide distribution of pore sizes, the distribution of which is not easily controlled, and these membranes are thick. Note the scale difference in the two panels - the panel on the left is on the nanometer scale while the panel on the right is on the micrometer scale.

When evaluating the interactions of pores with solutes and solvents at the atomic level, both the shape of the solvent sphere around the solute as it approaches the pore and the tightness with which the solvent molecules are bound to the solute will determine the amount of energy required to allow the solute to move through a particular pore. Pores have been developed such that the energy requirements to dehydrate ions are so great that they cannot be met, and restriction of ion movement through the pore occurs. Note that this is not related to the molecular size of the solute separate from its hydration shell, but can clearly differentiate the movement of different solutes across a pore. These concepts are illustrated in figure 6 and table 1. Note that magnesium, with a molecular weight of 24 , will have a more difficult time traversing the pore than calcium, with an identical charge and higher molecular weight. Pores can, therefore, be developed with similar radii, but with dramatically dif-
Table 1. Laboratory results: Smart pore passage of cationic solutes

\begin{tabular}{|c|c|c|c|c|}
\hline Solute & $\begin{array}{l}\text { Radius of } \\
\text { solute }^{\mathrm{a}}\end{array}$ & $\begin{array}{l}\text { Radius of } \\
\text { solute } \mathrm{w} / \mathrm{H}_{2} \mathrm{O}^{\mathrm{b}}\end{array}$ & Pore $1^{\mathrm{c}}$ & Pore $2^{\mathrm{d}}$ \\
\hline $\mathrm{Li}^{+}$ & 0.6 & $2.0(5.6)$ & No & Yes \\
\hline $\mathrm{Na}^{+}$ & 1 & 2.2 & Yes & Yes \\
\hline $\mathrm{K}^{+}$ & 1.3 & 2.7 & Yes & Yes \\
\hline $\mathrm{Ca}^{2+}$ & 1 & 2.7 & Yes & Yes \\
\hline $\mathrm{Mg}^{2+}$ & 0.7 & $2.8(5.5)$ & No & Yes \\
\hline $\mathrm{NH}^{4+}$ & 1.9 & 2.9 & Yes & Yes \\
\hline $\mathrm{Cs}^{+}$ & 1.7 & 3 & Yes & Yes \\
\hline $\mathrm{MeNH}^{3+}$ & 2 & 3 & Yes & Yes \\
\hline $\mathrm{EtNH}^{3+}$ & 2.6 & 3.6 & No & Yes \\
\hline $\mathrm{NMe}^{4+}$ & 2.6 & 3.6 & No & Yes \\
\hline Aminoguanidine & 3.1 & 4.1 & No & Yes \\
\hline Choline & 3.8 & 4.8 & No & Yes \\
\hline $\mathrm{Net}^{4+}$ & 3.9 & 4.4 & No & No \\
\hline Glucosamine & 4.2 & 5.2 & No & No \\
\hline $\mathrm{NPr}^{4+}$ & - & - & - & No \\
\hline \multicolumn{5}{|c|}{${ }^{a}$ Computed radius of solute in vacuum $(\AA)$. } \\
\hline
\end{tabular}

ferent and selective solute passage characteristics, as shown in table 1.

We have performed modeling studies of the performance of the HNF for urea, $\beta_{2}$-microglobulin, and a variety of other solutes. For these analyses we have assumed a 70-kg patient, total body water 42 liters, and a protein intake of $1.2 \mathrm{~g} / \mathrm{kg} /$ day. We have used a five-compartment model for these simulations. For the dialysis model, we have assumed a 4-hour treatment three times per week (Mon, Wed, Fri), no residual renal function, and a dialyzer with a urea clearance of $277 \mathrm{ml} / \mathrm{min}$ at a $\mathrm{Q}_{b}=$ $300 \mathrm{ml} / \mathrm{min}$ and a $Q_{d}=500 \mathrm{ml} / \mathrm{min}$. For the HNF model we assumed no residual renal function, a 12-hour treatment 7 days/week, with a blood flow of $100 \mathrm{ml} / \mathrm{min}$, and a $100 \%$ rejection of urea by the $\mathrm{T}$ membrane.

Simulating $30 \mathrm{ml} / \mathrm{min}$ glomerular filtration rate would result in a time-averaged urea concentration (TAC) in the modeled patient of about $27 \mathrm{mg} / \mathrm{dl}$, with minimal fluctuations of blood urea nitrogen throughout a weekly cycle. By contrast, the thrice-weekly dialysis simulation yields a TAC of $67.3 \mathrm{mg} / \mathrm{ml}$, with wide excursions of blood urea nitrogen reflecting the intermittent nature of the treatment. If the HNF were to run continuously, the TAC urea would fall to normal levels. 
Table 2. $\beta_{2}$-Microglobulin TAC (mathematical simulation)

\begin{tabular}{llllr}
\hline Modality & $\begin{array}{l}\text { Treatment } \\
\text { per week }\end{array}$ & $\begin{array}{l}\text { Assumed } \\
\text { dialyzer } \\
\text { clearance } \\
\text { ml/min }\end{array}$ & $\begin{array}{l}\mathrm{Qb} \\
\mathrm{ml} / \mathrm{min}\end{array}$ & $\begin{array}{l}\beta_{2} \mathrm{M} \\
\mathrm{TAC} \\
\mathrm{mg} / \mathrm{dl}\end{array}$ \\
\hline Standard & $4 \mathrm{~h}, 3$ days & 43 & 300 & 7.92 \\
Standard & $4 \mathrm{~h}, 3$ days & 78 & 300 & 5.25 \\
Short daily & $2 \mathrm{~h}, 7$ days & 43 & 300 & 6.50 \\
Short daily & $2 \mathrm{~h}, 7$ days & 78 & 300 & 3.96 \\
Nocturnal & $8 \mathrm{~h}, 7$ days & 37 & 200 & 1.94 \\
Nocturnal & $8 \mathrm{~h}, 7$ days & 66 & 200 & 1.24 \\
HNF-1 & $12 \mathrm{~h}, 7$ days & NA & 100 & 0.69 \\
HNF-1 & 18 h, 7 days & NA & 100 & 0.40 \\
Normal level & & & & $<0.27$ \\
\hline
\end{tabular}

We performed similar simulations for $\beta_{2}$-microglobulin, assuming free passage of $\beta_{2}$-microglobulin through the $\mathrm{G}$ membrane and $100 \%$ rejection by the $\mathrm{T}$ membrane. As shown in table 2, the ability of the HNF system to lower and sustain low levels of $\beta_{2}$-microglobulin com- pared to other dialytic approaches is apparent. With 12hour, 7-days/week treatment, levels of $\beta_{2}$-microglobulin are predicted to approach normal.

We have also modeled removal of key substances including sodium, potassium, calcium, magnesium, phosphorus, and bicarbonate. In a $70-\mathrm{kg}$ patient on a normal diet, the initial HNF system is capable of maintaining balance for all of these substances except bicarbonate, which may need additional supplementation.

In summary, the HNF system, by eliminating dialysate and utilizing a biocompatible membrane with an enhanced solute removal profile represents a breakthrough in RRT based on the functioning of native kidneys. Operating $12 \mathrm{~h} /$ day the HNF can provide the equivalent of $30 \mathrm{ml} / \mathrm{min}$ glomerular filtration rate. In addition, the wearable design permits full mobility and will improve patient quality of life. With provision of significantly greater solute removal than other dialytic approaches, and operating continuously, HNF is expected to significantly improve mortality and morbidity in this patient population as well.

\section{References}

1 US Renal Data System, 2003 Annual Data Report: Atlas of End-Stage Renal Disease in the United States. Bethesda, National Institutes of Health, National Institute of Diabetes and Digestive and Kidney Diseases, 2003.

$>2$ Kjellstrand CM, Evans RL, Petersen RJ, Shideman JR, von Hartitzsch B, Buselmeier TJ: The 'unphysiology' of dialysis: A major cause of dialysis side effects? Hemodial Int 2004;8:24-29.

$\checkmark 3$ Depner TA: Daily hemodialysis efficiency: An analysis of solute kinetics. Adv Ren Replace Ther 2001;8:227-235.

4 Lindsay RM, Kortas C, Daily/Nocturnal Dialysis Study Group: Hemeral (daily) hemodialysis. Adv Ren Replace Ther 2001;8:236249.

$\checkmark 5$ Pierratos A: Daily (quotidian) nocturnal home hemodialysis: Nine years later. Hemodial Int 2004;8:45-50.

6 Fagette P: Hemodialysis 1912-1945: No medical technology before its time. Part 1. ASAIO J 1999;45:238-249.

7 Fagette P: Hemodialysis 1912-1945: No medical technology before its time. Part 2. ASAIO J 1999;45:379-391.
8 Ronco C, Ghezzi PM, La Greca G: The role of technology in hemodialysis. J Nephrol 1999; 12:S68-S81.

$\checkmark 9$ Petitclerc T: Recent developments in conductivity monitoring of haemodialysis session. Nephrol Dial Transplant 1999;14:26072613.

10 Zimmerman DL: Hemofiltration as a treatment for end-stage renal disease. Hemodial Int 2004; 8:183-187.

11 Clark WR, Winchester JF: Middle molecules and small-molecular-weight proteins in ESRD: Properties and strategies for their removal. Adv Ren Replace Ther 2003;10:270-278.

12 Nissenson AR, Prichard SS, Cheng IK, Gokal R, Kubota M, Maiorca R, Riella MC, Rottembourg J, Stewart JH: Non-medical factors that impact on ESRD modality selection. Kidney Int 1993;40:S120-S127.

$>13$ Nissenson AR, Prichard SS, Cheng IKP, Gokal R, Kobuta M, Maiorca R, Riella MC, Rottembourg J, Stewart JH: ESRD modality selection into the 21st century: The importance of nonmedical factors. ASAIO J 1997;43:142-150.

14 Woffindin C, Hoenich NA: Hemodialyzer performance: A review of the trends over the past two decades. Artif Organs 1995; 19:11131119.
15 Clark WR: Quantitative characterization of hemodialyzer solute and water transport. Semin Dial 2001;14:32-36.

16 Ronco C: What clinically important advances in understanding and improving dialyzer function have occurred recently? Semin Dial 2001; 3:164-169.

17 Nissenson AR, Pergamit G, Edelstein M, Watts $\mathrm{R}$ : The human nephron filter-1 (HNF-1): Toward a continuously functioning, implantable artificial nephron system by applying nanotechnology (NT) (abstract). Am Soc Nephrol Annu Meet, 2003, www.asn-online.org.

18 Drexler KE: Introduction to nanotechnology; in Krummenacker M, Lewis J (eds): Prospects in Nanotechnology: Toward Molecular Manufacturing. New York, Wiley, 1995, p 7.

19 Voss D: Nanomedicine nears the clinic. Tech Rev 2000;Jan/Feb:60-65.

20 Rotman D: Quantum Dot Com. Tech Rev 2000;Jan/Feb:51-57.

21 Ronco C, Nissenson AR: Does nanotechnology apply to dialysis? Blood Purif 2001;19:347352. 